\title{
A geografia imaginativa no discurso extrativista no Peru
}

Lucia Fuchs-Sawert ${ }^{1}$

\section{Resumo}

A vertiginosa expansão das atividades extrativas no Peru, a partir do final do milênio passado, propiciou não apenas o crescimento econômico, mas também conflitos socioecológicos, que dizem respeito a mais do que distribuição de bens materiais, eles são pontos candentes no processo de negociação da identidade nacional e do pertencimento à nação. No Peru, impôs-se uma conceituação de território nacional como sendo formado por três regiões: Sierra, Costa e Selva. A ocorrência de recursos naturais se dá principalmente na Sierra e na Selva, o que influencia sobremaneira o papel dessas regiões no país. Este artigo aborda, via análise de discurso, como o ex-presidente peruano García (2006-2011) interpreta esses conflitos e como isto se relaciona com a construção histórica da geografia peruana. Desta análise sobressai-se que, no contexto de negociações sobre a exploração comercial de recursos naturais, adstrições racistas entram em cena. Através da referência a regiões geográficas, diferentes formas de conhecimento são hierarquizadas. Assim, protestos são deslegitimados, e o poder hegemônico de definir a identidade nacional é reforçado. O extrativismo torna-se daí um projeto de integração cultural e territorial sob a bandeira do progresso e do desenvolvimento, bem como um instrumento de reprodução do racismo e da desigualdade.

Palavras-chave: Extrativismo. Ecologia política. Análise de discurso. Espaço imaginativo. Conflitos socioecológicos.

\section{Abstract}

The boom of extractivism since the end of the last millennium has not only fuelled economic growth in Peru but also led to an increase of socioecological conflicts. Besides the distribution of material resources, they have become hotspots for the negotiation of national identity and belonging. The Peruvian territory is conceptionalised as consis-

\footnotetext{
${ }^{1}$ Doutoranda em Ciência Política na Universidade Livre de Berlin (Freie Universität Berlin). I.fuchs-sawert@transnationalstudies.eu

2 Doutor em Sociologia. Professor da Universidade Regional do Noroeste do Estado do Rio Grande do Sul (Unijuí). airtonmueller@hotmail.com
} 
ting of three regions: Costa, Sierra and Selva. Resource deposits are concentrated in the latter two, determining their role within the nation. The present paper examines with a discourse analytical approach how the former Peruvian president García (2006-2011) interprets the conflict and how this is related to the historic construction of Peruvian geography. It becomes clear that in the course of the negotiations about extractivism, racist attributions are applied. With reference to geographic regions, different bodies of knowledge are hierarchized. Protest is delegitimized and the hegemonic power to define the nation's identity is reinforced. Thus, extractivism becomes a project of cultural and territorial integration under the banner of progress and development and an instrument for reproducing racism and inequality.

Keywords: Extractivism. Political ecology. Discourse analysis. Imaginative space. Socioecological conflicts.

\section{Introdução}

Estas personas [comunidades nativas da selva peruana] no son ciudadanos de primera clase que puedan decir 400 mil nativos a 28 millones de peruanos: tú no tienes derecho de venir por aquí. [...] y quien piense de esa manera quiere llevarnos a la irracionalidad y al retroceso primitivo (GARCíA, 2009).

Esta declaração foi dada pelo ex-presidente peruano Alan Garcia Pérez em 5 de junho de 2009. Naquele dia, pelo menos 33 pessoas perderam suas vidas em consequência da repressão aos protestos contra a exploração de petróleo na Amazônia peruana. O confronto entre moradores das regiões atingidas (dentre os quais parte era composta por grupos indígenas) de um lado, e, de outro, o exército e a polícia, foi o ponto culminante de um dos inúmeros conflitos em torno da exploração de recursos naturais no Peru durante o governo García (ARRUENÁTEGUI, 2010). Embora o Peru tenha uma longa tradição de mineração, nas duas últimas décadas, o extrativismo atingiu, devido ao aumento dos preços no mercado mundial e da liberalização econômica, uma nova dimensão. Sobretudo o governo García (2006-2011) defendeu a promoção de um modelo econômico extrativista (BEBBINGTON, 2007). Considerando-se os indicadores macroeconômicos, este modelo foi bem-sucedido. Sobretudo os indicadores de crescimento da economia - em média de $7 \%$ ao ano - davam sustentação a García (CEPAL, 2012). Em paralelo, todavia, o número e a intensidade dos conflitos sociais relacionados à exploração de recursos naturais também aumentou (DE ECHAVE; HOETMER; PALÁCIOS PANÉZ, 2009).

Segundo os pressupostos da ecologia política, tais conflitos não são entendidos somente como conflitos referentes à distribuição de recursos naturais (MOECKLI; BRAUN, 2001; DIETZ, 2011). Eles são “[...] never simply about 'nature' or about 'meanings,' but about how the material world is rendered legible in and through ideas and concepts" (MOECKLI; BAUN, 2001, p. 125). Segundo Foucault (1983), trata-se de processos discursivos, nos quais tais ideias e conceitos são construídos e, através deles, o mundo é apreendido e interpretado. Esta interpretação não é neutra, mas determinada por estruturas sociais de poder que afetam qual interpretação se admite como uma 
"verdade" socialmente aceita (FOUCAULT, 1983). O resultado é uma relação estreita entre discurso, poder e espaço, porque "[...] strategies of power always require the use of space and, thus, the use of discourses to create particular spatial images" (SHARP, 1993 p. 492). Estas "imagens espaciais”, no Peru, são marcadas pela percepção de uma divisão natural entre as regiões Costa, Sierra e Selva, sendo que a cada uma delas são atribuídas distintas características. Estas "geografias imaginativas" específicas (RADCLIFFE; WESTWOOD, 1996) surgiram no decorrer do processo de construção da nação, no século 19, e se tornaram a forma predominante de conceber o território nacional (ORLOVE, 1993; MESCLIER, 2001; MÉNDEZ, 2011).

As representações imaginativas de territórios têm um impacto sobre o conflito em torno dos recursos naturais neles existentes. Referências relevantes para a conexão entre extrativismo e construção do espaço podem ser encontradas no estudo de Perreault (2013) sobre o "resource nationalism" na Bolívia, no qual o autor se atém ao papel das geografias imaginativas na constituição da Bolívia como petro-nação. Escobar (2008) analisa como a região pacífica colombiana foi construída como um Territory of Difference que deveria ser integrado à nação através de atividades extrativistas. De maneira semelhante, Asher e Ojeda (2009) abordam as políticas estatais de divisão territorial, que, segundo os autores, são estratégias para incorporar tal região à nação enquanto "'economically backward' but, biodiversity rich'". Tais obras dão indícios da importância do processo de construção das nações. As narrativas, representações e as estruturas de poder surgidas neste processo tiveram importância capital na forma de construção e/ou "invenção" do corpo físico da nação, particularmente no caso peruano em questão. Portanto, discute-se a seguir qual relação se dá entre a natureza, a nação e seus habitantes no âmbito de conflitos em torno de recursos naturais.

\section{Progresso, natureza e a nação}

A existência de projetos extrativistas, que estão na base da maioria dos conflitos socioecológicos no Peru, é justificada através de sua contribuição ao desenvolvimento e ao progresso (ALIMONDA, 2011). Nesse sentido, ressalta Bebbington (2007, p. 31) que "[...] la definición dominante del desarrollo - y por lo tanto la relación deseada entre desarrollo y medio ambiente - no es otra cosa que un artefacto del poder". As elites latino-americanas seguem uma concepção eurocêntrica, linear de modernização (ESCOBAR, 2008; ALIMONDA, 2011). Daí resulta uma visão binária, que interpreta o mundo em pares de opostos: por um lado, encontra-se o moderno, a racionalidade, a cultura e, por outro lado, o tradicional, o irracional, a natureza. Isso leva a uma concepção linear de modernização, segundo a qual o assim chamado "mundo desenvolvido" serve de modelo e parâmetro a ser seguido pelo resto do mundo a caminho da modernidade (ESCOBAR, 2007).

Decorre disso uma relação com a natureza, percebida como um recurso a ser usado no processo de produção capitalista (ESCOBAR, 2008; DIETZ, 2011). Recursos naturais são, assim, vistos como propriedade da nação, como patrimônio nacional, como "[...] the inheritance of the nation and its citizens, which is imbued with historical significance and 
purpose through its ability to promote national growth and modernization" (PERREAULT; VALDIVIA, 2010, p. 691). Quem não compartilha dessa concepção comete, segundo as palavras de Garcia citadas na introdução deste artigo, "[...] un error gravísimo y [...] quiere llevarnos a la irracionalidad y al retroceso primitivo".

A oposição ao extrativismo, seguindo esta lógica, tem de ser violentamente reprimida. Conflitos sobre a extração de recursos tornam-se, assim, pontos focais para a negociação de pertença à nação (SUNDBERG, 2008; PERRAULT; VALDIVIA, 2010; PERRAULT, 2013). Nações são, segundo Anderson (1996), "comunidades imaginadas", baseadas na invenção de uma identidade comum, de uma história compartilhada e de objetivos comuns dos seus cidadãos. Desde a independência, o objetivo ideológico da maioria das repúblicas latino-americanas é "[...] el de progreso, cuya llave estaba en manos de la cultura occidental y de la raza blanca indoeuropea" (QUIJADA, 2000, p. 11). No Peru, a população indígena, com sua cultura diferente, foi considerada como um obstáculo ao progresso e responsabilizada pelo atraso em relação aos EUA e à Europa (MÉNDEZ, 2011). Práticas indígenas de uso da natureza, bem como a cultura indígena como um todo foram, consequentemente, excluídas da identidade da nação (SUNDBERG, 2008).

\section{A invenção da geografia}

Como parte do processo de invenção de uma nação, tem-se não apenas a invenção de seus cidadãos e de sua história, mas também a invenção de sua geografia (ANDERSON, 1996). No contexto de conflitos em torno de recursos, que inevitavelmente ocorrem em espaços concretos, a invenção da geografia é de particular importância, uma vez que o lidar com tais espaços depende da sua concepção conceitual. $O$ espaço geográfico adquire uma dimensão simbólica, cujas paisagens e habitantes são representados e dotados de significado, do que resulta uma "geografia imaginativa" (imaginative geography) (RADCLIFFE; WESTWOOD, 1996). Nogués (1998, p. 60) destaca o caráter produzido de territórios, segundo o qual "[...] son las acciones y los pensamientos humanos los que dan sentido a una porción cualquiera del espacio y la convierten en territorio. El territorio, per se, no existe, sino que se hace". Como estímulo para este fazer dos territórios, ele vê o desejo de controle sobre espaços. O território torna-se, assim, uma "expresión geográfica del poder". A produção de diferentes territórios dentro de uma nação é, portanto, indissociável das estruturas sociais de poder deste território.

Os países latino-americanos surgiram de unidades administrativas coloniais. Portanto, a partir de uma área aleatória, o novo território nacional teve que se tornar o território natural da nação. Precisava ser mistificado, dotado de significado e conectado à sua população nacional e à sua história (ANDERSON, 1996). Dessa forma, as áreas que foram construídas como dominadas pela natureza, portanto, (ainda) não eram parte da civilização nacional, foram associadas discursivamente, por meio do acima descrito quadro qualificador binário, a noções de atraso, irracionalidade e passividade (MOECKLI; BRAUN, 2001; DIETZ; 2011). Em contraposição à cultura crioula, urbana, orientada pelos ideais ocidentais de progresso, encontra-se a cultura indígena, classificada como retrógrada e rural (SUNDBERG, 2008; LINDNER; STETSON, 2009). Assim, paisagens e práticas 
de utilização da natureza oferecem uma superfície de projeção, sobre a qual a diferença étnica e social passa a estar fadada a desaparecer ao ser naturalizada, ou seja, ao ser mostrada como parte da natureza (DIETZ, 2011).

\subsection{As regiões "naturais" do Peru}

A conceituação do território nacional do Peru é caracterizada por limites internos que dividem o país em três "[...] regiones naturales: Costa, Sierra e Selva" (ORLOV, 1993; MESCLIER, 2001). No seu conjunto, elas formam a geografia imaginativa da nação. Nesta geografia, as regiões foram hierarquizadas, compondo uma imagem da nação segundo a qual a região Costa e especialmente a capital, Lima, localizada em seu centro, é apresentada como o centro civilizado da nação. É o lugar da cultura crioula, da economia capitalista desenvolvida e da população supostamente esclarecida (ORLOVE, 1993; MESCLIER, 2001; MÉNDEZ, 2011). A Sierra é considerada uma região arcaica, que representa, física e culturalmente, um obstáculo ao progresso da nação ( $\mathrm{VICH}, 2010)$. Além disso, no que tange à naturalização da diferença, ela é tida como o "lugar natural del Indio" (MÉNDEZ, 2011, p. 86). A região da Selva é a que costumeiramente recebe menos atenção: "[...] the selva and its indigenous inhabitants have historically been tacked on as a mere 'appendix' to the nation"(GREENE, 2010, p. 337). Ela costuma ser vista sob completo domínio da natureza. Seus habitantes são vistos da mesma forma (LINDNER; STETSON, 2009), ou simplesmente ignorados (GRILLO; SHARON, 2012). Mas a percepção sobre ela também inclui a promessa de grandes riquezas (PIZARRO, 2005, p. 63). Atualmente é a existência de reservas de petróleo que desperta a cobiça de muitos. A divisão tripartite do território peruano passou a ter um status tão universal que costuma ser considerada como a forma natural do corpo físico da nação (MESCLIER, 2001).

\section{0 discurso sobre o espaço e o extrativismo}

Via Análise de Discurso ${ }^{3}$, foram analisados três ensaios do ex-presidente peruano García Perez. Tais ensaios foram publicados com destaque em edições dominicais do jornal El Comercio 4 durante o período de outubro de 2007 a março de 2008. Além disso, foi analisado um material histórico-geográfico para evidenciar a estrutura espacial subjacente. Os resultados foram, por fim, interpretados tendo em vista a política extrativista atual. Os textos escolhidos, na opinião de especialistas (por exemplo MÉNDEZ, 2011; ALIMONDA, 2011), influenciaram fortemente o discurso em torno da exploração

\footnotetext{
${ }^{3}$ Análise de Discurso envolve um procedimento qualitativo cuja base se encontra sobretudo na obra de Michael Foucault. Através deste procedimento, busca-se a desconstrução da realidade socialmente percebida e suas relações de poder (JÄGER, 2012). O acesso ao espaço público e daí ao discurso não está distribuído uniformemente, mas é dependente das estruturas de poder social (BRAIG; HUFFSCHMID, 2009).

${ }^{4}$ O jornal El Comercio é o mais antigo e de maior prestígio no país (ARRUNÁTEGUI, 2010). Os artigos foram publicados num momento estratégico, pouco antes da ratificação de um acordo de livre comércio com os EUA. Tal acordo visava facilitar a exploração dos recursos naturais na região amazônica por empresas internacionais. Os protestos contrários a tal acordo culminaram no incidente acima descrito.
} 
de recursos naturais. Neles, García descreve suas ideias para o desenvolvimento do país através da exploração de recursos naturais. A isso haveria, no entanto, forças hostis se opondo. Sua imagem símbolo do inimigo é o "Perro del Hortelano", o cão do jardineiro. Essa imagem vem de uma fábula antiga e refere-se a um cão que defende o canteiro de vegetais de seu proprietário contra outros animais. Ele próprio não usa/consome os legumes, porém não admite que outros possam fazê-lo.

\subsection{Estrutura dos atores: alianças e imagens do inimigo}

García traz à cena diferentes atores que podem ser caracterizados a partir de pares de opostos, como moderno / retrógrado, racional / irracional. O texto é dirigido ao povo peruano e é escrito na primeira pessoa do plural. O ex-presidente escreve como parte do povo para o povo. Isso, porém, não significa referência a todos os habitantes de maneira equânime. Ele escreve: "[...] cualquier peruano que mire a su alrededor verá cuánta riqueza existe que no está puesta en valor"(GARCÍA, 2007a). Um peruano é, por conseguinte, apenas aquele que, tal qual García, enxerga a natureza sobretudo como um recurso rentável. A estes é contraposta a imagem do inimigo, que se sobressai nos artigos, o que se dá de maneira abstrata no título através da imagem do "perro del hortelano". A razão pela qual o Peru não estaria podendo utilizar seu potencial seria "la ley del perro del hortelano, que reza: Si no lo hago yo que no lo haga nadie" (GARCÍA, 2007a). Os grupos que ele associa com a imagem do inimigo vão desde pessoas que vivem da agricultura de subsistência, até ativistas políticos. Na maioria dos casos, todavia, o oponente permanece anônimo. Da imagem deste inimigo, conforme dito, faz parte sua representação como sendo irracional e retrógrado.

Também aparecem, de maneira menos explícita, atores aliados. Eles representam uma tela de projeção para as soluções propostas por García. Nesse rol, García menciona atores empresariais, como os "grandes capitales privados o internacionales" (GARCíA, 2007a), e também "[...] los pueblos exitosos, los alemanes, los japoneses, los coreanos y muchos otros" (GARCíA, 2007a). García apresenta os países "desenvolvidos" como modelos a serem seguidos, e os atores do sistema econômico capitalista como os aliados para atingir seus objetivos, que seriam compartilhados por todos os peruanos tidos como racionais.

\subsection{A nação enquanto empreendimento econômico: progresso como objetivo do Estado}

O estilo predominante dos artigos é o que poderíamos chamar de tecno-econômico. Já no início do primeiro artigo, García resume sua leitura da situação no Peru conforme segue: "Muchos de sus bienes no se pueden poner en valor, ni vender, ni se puede invertir en ellos, ni generar empleos con ellos" (GARCÍA, 2007a). Pelo tom e a terminologia, o então presidente peruano se vale do repertório discursivo do mundo dos negócios. A nação é representada de maneira análoga a uma empresa, e, como tal, o Peru precisa de capital. Entretanto, teoricamente, não há falta dele, pois "[...] cualquier peruano que mire a su alrededor verá cuánta riqueza existe” (GARCÍA, 2007a).

Estas riquezas são, entre outras, "[...] recursos mineros en los que el Perú tiene 
la riqueza más grande del mundo" (GARCÍA, 2007a), “[...] las caídas de agua, que son la riqueza más grande que tiene el Perú" (GARCÍA, 2007b) ou "[...] la riqueza forestal de la Amazonía" (GARCÍA, 2008). Os recursos naturais deveriam ser explorados por investidores privados, com tecnologias modernas e em larga escala, para que o Peru, tal qual [...] la experiencia de los pueblos exitosos" (GARCÍA, 2007a), possa vir a ser algo semelhante aos países industrializados do ocidente. Para García, a natureza é sinônimo de recursos econômicos, outras visões não são mencionadas, ou são ridicularizadas [...] están en contra de la inversión forestal en la selva porque es sagrada [...]" (GARCÍA, 2007a). Ele usa uma imagem que tem uma longa tradição no Peru. A saber, aquela referente ao "mendigo sobre o banco de ouro". A ideia de desequilíbrio entre o que o Peru poderia ter e o que tem em termos de desenvolvimento foca o orgulho nacional do leitor quando ele diz que "[...] es una vergüenza que Chile exporte US\$2.000 millones en madera sin tener una hectárea de Amazonía" (GARCÍA, 2007a). A exploração e uso dos recursos nacionais torna-se, assim, um projeto pelo qual a nação tem que provar a si mesma suas capacidades.

4.3 La telaraña ideológica del siglo XIX subsiste como un impedimento: forças de bloqueio

No lado oposto a tais ideias, está “[...] el tabú de ideologías superadas, por ociosidad, por indolencia o por la ley del perro del hortelano". García aborda argumentos de ordem religiosa, ecológica e os relativos a direitos civis, sendo apresentados todos como se fossem ideologias superadas e opostas à Modernidade. "[...] dicen que se está bloqueando su derecho al libre paso, que se contamina el mar y otros invocan lo sagrado del Mar de Grau" (GARCíA, 2007a). Tudo que contraria a percepção de desenvolvimento de García é depreciado como sendo retrógrado e irracional, como sendo "la telaraña ideológica del siglo XIX" (GARCÍA, 2007a). Assim, o "perro del hortelano" é entendido como um bloqueio interno da nação. Aquelas crenças classificadas como retrógradas devem ser superadas, para que surja uma nação moderna, com cidadãos iguais uns aos outros. Para García, tal condição ainda não foi atingida, todavia, afirma ele, os "comuneros de la Sierra" estariam condenados a uma vida como [...] ciudadanos de segunda clase y sin iniciativa" (GARCÍA, 2007b).

\subsection{Para que al final todo estalle: ameaça, guerra, caos}

O "perro del hortelano" ameaça o desenvolvimento da nação também de forma ativa, isto na forma do "antiminero pluriculturalista y patriotero" (GARCíA, 2008). García emprega uma retórica de guerra ("lucha", "batalha", "tropa", etc.) e atribui àqueles que se opõem ativamente aos projetos extrativistas, o movimento de uma guerra contra a nação. Neste intento, ele emprega o símbolo coletivo do comunismo: "El viejo comunista anticapitalista del siglo XIX se disfrazó de proteccionista en el siglo XX y cambia otra vez de camiseta en el siglo XXI para ser medioambientalista" (GARCÍA, 2007a), que, no Peru, desperta memórias sobre as ações, nos anos 1980-1990, do grupo guerrilheiro maoísta Sendero Luminoso. Tal associação visa despertar medo nos leitores. Ativistas contra a ex- 
ploração dos recursos naturais são transformados, pela via discursiva, em terroristas que ameaçam não só o desenvolvimento da nação, mas que também se esforçam para que "[...] al final todo estalle" (GARCÍA, 2008). Nesse sentido, há que se lembrar que no Peru o medo do suposto terrorismo possui um componente racista. O Sendero Luminoso foi injustamente associado aos indígenas da área rural da Sierra, conexão esta que perdura até hoje (VICH, 2010).

\subsection{Regiões “Naturais"}

Em seus artigos, García traça uma imagem do corpo físico do Peru como o território que pertence à nação, cujos recursos naturais devem ser usados em favor dela. Aos textos subjaz um conceito de ordenamento espacial inequivocamente ligado à costumeira divisão tripartite do território nacional, sendo que cada região é explicitamente diferenciada das demais. "Los que se oponen dicen que no se puede dar propiedad en la Amazonía (¿y por que sí en la costa y en la sierra?)» (GARCíA, 2007a).

A região costeira é apresentada como a menos conflituosa e tida como um bom exemplo para as demais regiões. Os solos da Costa, usados de maneira intensiva, salinizam-se porque os solos da Selva não são usados. Característica elementar da região costeira é a capital do país (Lima), que, com seus sete milhões e meio de habitantes, representa, em quase todos os sentidos, o centro do Estado. Isso é assim tão claro, inclusive para García, que ele escreve sem nem mesmo assinalar à qual cidade está se referindo: "[...] el provinciano invade en los cerros de la ciudad" (GARCÍA, 2007b). Assim, ele cria uma dicotomia entre Lima e o resto do território nacional.

No geral, a Costa é mencionada em todos os três textos apenas em contraste com as outras regiões, não havendo referências sobre ela em si. Tal fato se conecta com a estrutura dos atores, no sentido de que a identidade do "nós peruanos racionais" se situa em Lima.

A Sierra é contrastada negativamente com a Costa e associada aos agitadores-ativistas inimigos da nação, tal como nos tempos de Guerra Civil. Outro problema seria as:

Comunidades [campesinas] artificiales, que tienen 200 mil hectáreas en el papel pero solo utilizan agrícolamente 10 mil hectáreas y las otras son propiedad ociosa, de 'mano muerta', mientras sus habitantes viven en la extrema pobreza y esperando que el Estado les lleve toda la ayuda en vez de poner en valor sus cerros y tierras, alquilándolas, transándolas porque si son improductivas para ellos, sí serían productivas con un alto nivel de inversión o de conocimientos que traiga un nuevo comprador (GARCÍA, 2007a).

A Sierra é, para García, um lugar ocupado por "comunidades campesinas" que não seriam capazes de usá-la em benefício da nação, e, apesar disso, negam-se a permitir que isso ocorra porque "La demagogia y el engaño dicen que esas tierras no pueden tocarse porque son objetos sagrados y que esa organización comunal es la organización original del Perú, sin saber que fue una creación del virrey Toledo para arrinconar a los indígenas en las tierras no productivas" (GARCÍA, 2007a). A região da Sierra seria o lugar para onde os índios foram "empurrados" durante o período colonial. No entanto, os indígenas não estariam esclarecidos suficientemente sobre tal fato e, assim, apresen- 
tar-se-iam como vítimas. A inércia e a falta de consciência levariam ao "bloqueio" das terras para a nação, o que significa um obstáculo ao progresso. Aqui se torna evidente a associação direta feita pelo ex-presidente entre a população indígena e seus valores culturais com a geografia da Sierra.

Enquanto, na visão de García, na Sierra o progresso é impedido pelos habitantes, ele afirma que a Selva "[...] el primer recurso es la Amazonía. Tiene 63 millones de hectáreas y lluvia abundante" (GARCÍA, 2007a). A Amazônia é, assim, vista como um único recurso, diferentemente do que acontece com a Sierra. No caso da Selva, nunca é explicitamente mencionado quem seriam os oponentes de seu uso produtivo. Somente é mencionado que "[...] los que se oponen dicen que no se puede dar propiedad en la Amazonía (¿`y por que sí en la costa y en la sierra?)" (GARCíA, 2007a). Os únicos moradores mencionados são, segundo García, fruto de lendas inventadas por atores mal-intencionados.

Contra el petróleo, han creado la figura del nativo selvático 'no conectado'[sic!]; es decir, desconocido pero presumible, por lo que millones de hectáreas no deben ser exploradas, y el petróleo peruano debe quedarse bajo tierra mientras se paga en el mundo US\$90 por cada barril. Es preferible para ellos que el Perú siga importando y empobreciéndose (GARCÍA, 2007a).

Também aqui se repete a imagem de um espaço isolado e desabitado, "una tierra de nadie" (GARCÍA, 2007b). Isso, entretanto, não deve mais persistir, pois ele tem grandes planos para a região. Por exemplo, construir "grandes centrales eléctricas hechas sobre el Marañón y en las caídas del bajo Urubamba, [que] nos permitirán vender energía a Ecuador, Colombia, Chile, Brasil" (GARCÍA, 2008). Além disso, García se mostra decidido a acabar com o suposto isolamento da região através de "obras de la Interoceánica Norte [...] que facilitará la conexión y el comercio con zonas hasta ahora aisladas" (GARCÍA, 2008). Mesmo que na Sierra e na Selva existam grandes cidades, tais regiões, nas descrições de García, parecem ser exclusivamente rurais (Sierra) e desabitadas (Selva).

\subsection{Conclusão intermediária: El Perro del Hortelano contra a nação}

Em seus ensaios, García expõe sua interpretação da nação peruana. Em termos de um ideal linear de modernização, eles visam à transformação do Peru em um Estado moderno, a exemplo dos Estados ocidentais. A ideia de nação tem, neste caso, dois níveis: de um lado, ela consiste em um território nacional, e, de outro, em seus cidadãos. O território abrange toda a área dentro das fronteiras do Estado, mas a cidadania é limitada às pessoas que compartilham da visão de mundo de García. Isso significa que os dois níveis não coincidem: não é todo o território que é habitado por cidadãos. García gera uma interpretação da natureza segundo a qual ela é um recurso econômico que deve ser dominado e explorado economicamente pelo homem. Essa interpretação é, para ele, a única racional. Através disso, García destitui de racionalidade pessoas com outros pontos de vista e, assim, nega seu pertencimento a uma nação peruana moderna.

Desta interpretação da natureza resulta que a nação, enquanto proprietária do território e de todos os seus tesouros naturais, deveria ser rica. Com a ajuda de investidores que, ao contrário do Estado peruano, são possuidores de tecnologia moderna, 
poderia a nação valer-se desta riqueza para efetivar o objetivo nacional de transformar o Peru em um Estado moderno. Isso, no entanto, estaria sendo impedido pelos moradores que não se enquadram no perfil de cidadão traçado por García, mais precisamente, pelos "perros del hortelano", aqueles que não exploram os recursos existentes em suas regiões e também não permitem que outros o façam. Eles impediriam, assim, o desenvolvimento da Nação.

Dessa forma, adstrições culturais são naturalizadas. Quanto mais uma região está afastada do centro da modernidade, Lima, menos civilizada ela parece e, assim, também seus habitantes. Os inimigos da nação, sejam eles ativos ou passivos, são, dessa forma, alocados na Serra e na Selva. García desperta raiva em seus leitores em relação a essas regiões que não estão dispostas a compartilhar suas riquezas com a nação, enquanto o Estado civilizado da Costa luta para alimentá-las. Assim, ele estiliza o extrativismo como um projeto de integração nacional. Cada região deve contribuir para o desenvolvimento do Peru. A Sierra, superando seu atraso cultural, e a Selva, fornecendo suas imensuráveis riquezas a serviço da nação e do progresso. Nos "peruanos racionais" da Costa (especialmente de Lima), Garcia alimenta o medo frente ao incivilizado "outro" da Sierra e da Selva. Aqui o recurso à estrutura espacial serve como uma metáfora para falar sobre a raça sem qualquer tipo de sanção. As adstrições culturais e as estruturas sociais de poder que, através da referência à estrutura espacial, permeiam o discurso, tornam-se evidentes a partir de um olhar sobre a construção histórica do ordenamento territorial peruano.

\section{A construção histórica do espaço - integração do território nacional}

A história mostra que a divisão tripartite (Costa, Sierra, Selva) não é a única forma possível de interpretar o território peruano. Assim, durante a domínio inca (aproximadamente: 1438 - 1533), a cidade de Cusco (em quéchua: umbigo do mundo), localizada mais a sul do que Lima, foi a capital do império. Isso mudou com a invasão espanhola em 1533. Lima, anteriormente um povoado insignificante na costa, torna-se em "Ciudad de los Reyes" e o centro do império colonial (1542-1821). Império este que foi descrito em antigos textos de geografia como um território marcado pela diversidade cultural e paisagística (ORLOVE, 1993). A cidade foi capaz de manter esta posição após a independência (1821). A representação do território nacional, no entanto, mudou durante o período republicano, fazendo surgir a divisão tripartite em três regiões relativamente homogêneas e distinguíveis umas das outras (ORLOVE, 1993).

Após a independência frente à Espanha, uma identidade nacional que justificasse a dominação das elites crioulas sobre o país diverso e sua população tinha de ser forjada. Assim, teve de ser definido onde seriam as fronteiras internas e quem ocuparia qual lugar dentro da nação (QUIJADA, 2000). Paralelamente ao surgimento da nova república, impôs-se uma nova forma de produção geográfica que forneceu as ferramentas para uma invenção da geografia ${ }^{5}$. Geografia agora não era mais baseada em impressões

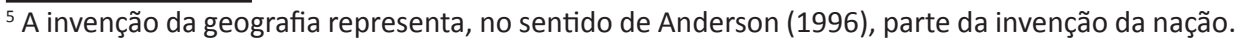


subjetivas, como na era colonial, mas passou a ser baseada em métodos científicos para determinar altitudes, distâncias e outros parâmetros (ORLOVE, 1993; PIZARRO, 2005; MÉNDEZ, 2011). Estes novos conhecimentos sobre o corpo físico da nação foram usados para fixar a diversidade cultural e étnica em sua geografia, do que resultou que a Costa passou a ser vista como a região dos brancos, a Sierra como a região dos indígenas e a Selva como a região de ninguém, ou dos selvagens.

De particular importância para a consolidação e divulgação desta nova interpretação do território foram duas obras: Geografia del Peru (1862) e o Gran atlas del Perú (1865), dos irmãos Paz Soldán. Assim, pode-se ler na Geografía del Perú: "Esta natural configuracion del terreno da lugar á clasificarlo en tres zonas, enteramente distintas en clima, productos, topografia y porvenir industrial y social" (PAZ SOLDÁN, 1862 p. 20). Esta cartografia tem um papel especial a desempenhar, porque um mapa mostra claramente os limites da nação, tornando-se um símbolo da inclusão e exclusão do conhecido e do estranho, respectivamente (ANDERSON, 1996 p. 163). Tendo em vista que a elaboração de mapas se dá com base em medições supostamente exatas, tal representação traz consigo uma reivindicação especial de objetividade (MICHEL, 2010). Neste processo, a altitude desempenhou papel primordial.

\subsection{A invenção do altiplano}

Enquanto que no período colonial as representações das paisagens se alternavam entre pequenas montanhas e planícies, surge, com a cartografia do período republicano - e a medição de uma altitude absoluta acima do nível do mar - uma nova imagem: o altiplano. Ao definir os limites dos Andes a leste e a oeste, passaram a representá-los um bloco maciço que dividia o território em três partes, estando a Costa localizada a oeste dos Andes e a Selva a leste, do que resulta que as duas regiões não estão em contado uma com a outra (ORLOVE, 1993). Tal divisão tripartite tornou-se uma forma usual de representação da nação, tornou-se um map-as-logo, no sentido de Anderson (1996, p. 175), para a nação.

Embora diferentes geógrafos escolhessem diferentes altitudes para definir as fronteiras, todos concordaram em definir as terras altas como um bloco sólido, que atravessa o país de norte a sul (ORLOVE, 1993). Assim, a representação do espaço passa de um mosaico de diferentes culturas, etnias e espaços naturais a um ente uniforme, cuja diversidade passou a ser restrita às suas três regiões "naturais" e internamente "homogêneas". Tais regiões são hierarquizadas discursivamente com o fito de trasladar as relações de poder prevalecentes historicamente para o agora Estado republicano.

A Figura 1, inserida na próxima página, proveniente do Gran Atlas del Perú, ilustra a representação do altiplano enquanto característica marcante do país. Tanto as embarcações que aparecem no oceano, quanto as cidades - pontos minúsculos nas montanhas - aparentam insignificância e desprovidas de poder. O tamanho das montanhas é mostrado de maneira desproporcional, o que é reforçado pela perspectiva. Através da posição do mar em primeiro plano, o território é visto a partir daquele ponto. A vista, portanto, vai da Costa para a Sierra. 


\section{Figura 1 - Quadro General de Alturas Comparativas del Perú}

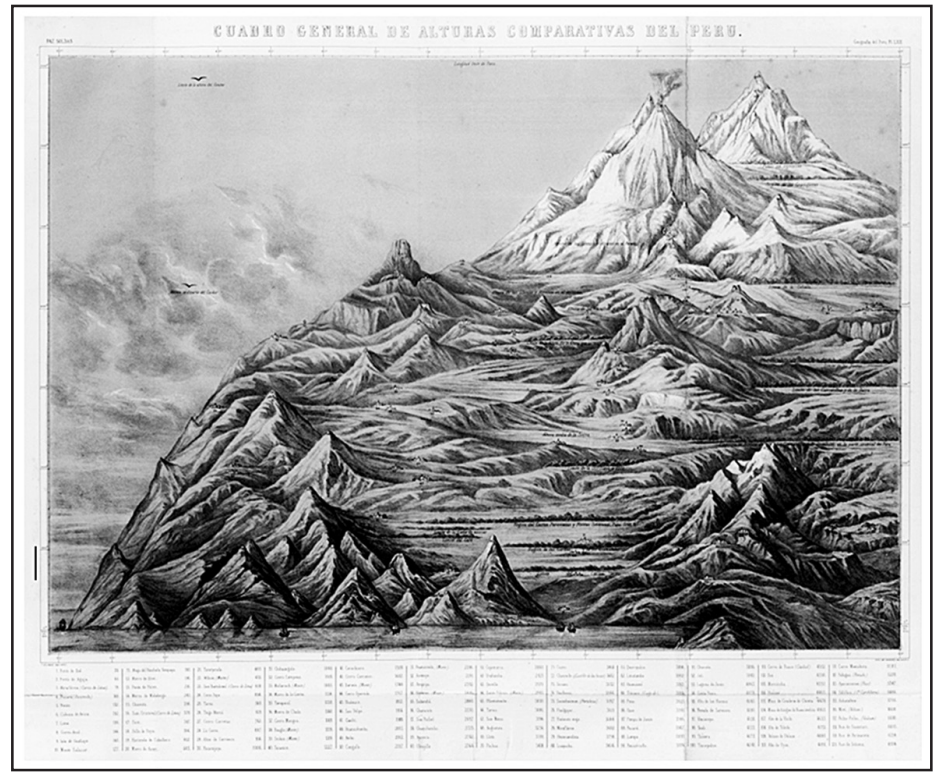

Fonte: Paz Soldán (1865).

Para a identidade nacional da jovem república, surge, a partir da figura, uma clara mensagem. Em frente ao centro da república, situado em Lima, ergue-se um obstáculo intransponível: a Sierra. Como uma das três regiões do país cabe a ela a função de dividir o território. Superá-la é o desafio da nação. Ela, a Sierra, com sua altura e forma, mostrase ameaçadora e rígida, estática e improdutiva. Dessa forma, ela é contraposta à Costa, que, por sua vez, mostra-se, conforme a imagem dos navios em seu entorno, acessível e laboriosa. Tais características construídas discursivamente foram, no processo de construção da nação, associadas não só à natureza, mas também ao seu povo. Enquanto que na era colonial se representava uma população indígena heterogênea e presente em todo o território peruano, na república essa população passa a ser fortemente associada à Sierra e construída como um grupo homogêneo com características fixas (ver. inter alia MÉNDEZ, 2011; VICH, 2010).

Sobre "el infortunado Indio", Paz Soldán (1862, p. 30) escreve: "En esas áridas y glaciales serranías devora en silencio sus agudos dolores y sus multiplicadas tribulaciones. Y sus danzas y sus cantos y sus diversiones no son las danzas, los cantos, ni las diversiones del hombre de otros lugares". O "Índio" e a paisagem andina são igualmente representados como sendo essencialmente passivos, tristes, pobres e isolados. A geografia dos Andes passa a ser, dessa forma, um local de refúgio: "[...] se retiran á las Punas los mas de ellos á vivir miserablemente" (PAZ SOLDÁN, 1862, p. 337). No entanto, também na percepção da população crioula do século 19 a população indígena era tida como a formadora da maioria dos habitantes (PAZ SOLDÁN, 1862, p. 24). A associação com a serra fornece uma maneira de marginalizar a maioria da população, por ser ela representada como uma região periférica e ligada ao passado. A Sierra se torna uma me- 
táfora para a representação da população indígena. Ela é situada no entrecruzamento de um obstáculo desolador e estático, por um lado, e de uma poderosa e incontrolável ameaça, de outro. Assim, tanto a Sierra quanto os indígenas passam a ser um obstáculo ao progresso e uma ameaça às relações de poder estabelecidas.

A Selva, "la última y á la mas rica zona del Perú" (PAZ SOLDAN, 1862, p. 146) é separada do centro da nação pela Sierra. Como "terreno virgen, donde la civilización todavía no ha penetrado" (PAZ SOLDAN, 1862, p. 146), ela é mostrada como uma região natural, desabitada e rica, porém, por enquanto, inacessível. Apesar de as pessoas que lá vivem terem sua existência reconhecida (o livro contém descrições detalhadas de diferentes "tribus de salvajes"), devido ao fato de não serem civilizadas - no sentido de Paz Soldan - elas não são representadas como cidadãos iguais, mas sim como parte da natureza em si. Diferentemente da população indígena da Sierra, a população da Selva não é vista como relevante para a nação: seja como parte dos cidadãos peruanos, seja como ameaça.

\subsection{Estrutura espacial e conflitos em torno de recursos}

Ao se observar tais interpretações, juntamente com o discurso governamental acima analisado, pode-se afirmar que a representação da Costa pouco se altera na comparação com a geografia do período republicano. Ela é o território dos cidadãos racionais do Peru. A apresentação da Sierra, por sua vez, apresenta continuidades e rupturas. Tanto em García quanto em Paz Soldan, ela é descrita como um lugar do passado e da irracionalidade. A população, que de uma maneira ou outra é categorizada como indígena, é mostrada como passiva e vivendo em condições precárias. Aos Andes são atribuídas por García características similares àquelas destacadas por Paz Soldan. Suas funções dentro da nação, no entanto, mudam. Enquanto que nas obras historiográficas aqui analisadas eles (os Andes) aparecem como uma barreira intransponível, em García, eles são uma barreira cultural, porém geograficamente transponíveis. Entretanto seu aspecto ameaçador, que se expressa principalmente na representação visual em Paz Soldan (Figura 1), não se desfez por completo no século 21. Isso fica claro nas referências de García ao terrorismo e ao vinculá-lo ao ativismo ambiental. Dessa forma, o seu aspecto ameaçador é trasladado ao século 21 e associado aos conflitos em torno de recursos naturais. O reconhecimento como "cidadãos iguais" só pode ser alcançado através de um ajustamento à ordem do conhecimento dominante. O direito à voz, a partir de uma posição de diferença, não lhes é permitido, mesmo quando se trata de projetos que afetam diretamente seu habitat.

A representação da Selva mostra um quadro semelhante ao da Sierra. Sua caracterização mudou pouco ao longo do tempo, sua função para a nação, entretanto, mudou enormemente. Em todas as representações, a Selva é uma região de natureza dotada de riquezas fabulosas. A isso está intimamente associada uma imagem de ausência de civilização. Embora ambos, Paz Soldan e García, mencionem a existência da vida humana na Selva, esta não é percebida como um habitat. Os constructos discursivos, dessa forma, distinguem-se. Paz Soldan descreve em detalhes a população da Selva, mas não a classifica como cidadãos civilizados da nação. Em função de atuais regras discursivas 
"politicamente corretas", tal opção se mostra inviável para García. Ele opta, então, por negar totalmente a existência de população na Selva. Em Paz Soldan, a Selva é um apêndice da nação; em García, ela se tornou unicamente num recurso econômico que precisa ser explorado.

O fato deste posicionamento do Governo ser acompanhado por um aumento acentuado dos conflitos sociais, pode ser vislumbrado através de dados da Defensoría del Pueblo. Eles mostram que, entre 2008 e 2009, ou seja, após a publicação dos artigos de García, o número de conflitos socioecológicos em todas as três regiões cresceu consideravelmente. Na Costa, isto foi na ordem de 173\%; na Sierra, 163\% e, na Selva, o aumento chegou a $500 \%$, sendo, assim, claramente a região onde os conflitos mais se proliferaram (DEFENSORÍA DEL PUEBLO, 2014).

\section{Conclusão: integração através do extrativismo}

No âmbito do discurso sobre o extrativismo no Peru, são negociadas as relações entre a nação, seu corpo físico e seus cidadãos. García faz da aprovação a um modelo extrativista-liberal a questão crucial de pertença à nação. A partir de um paradigma de desenvolvimento linear, o extrativismo é apresentado como o único caminho rumo a uma modernidade idealizada. Cidadãos racionais apoiam o extrativismo, quem a ele se opõe passa a ser inimigo da nação. Estreitamente associada a isso está a necessidade de uma definição da natureza segundo a qual ela seja vista como um recurso e, decorrente disso, dá-se como única consequência racional possível sua exploração econômica. Assim, todos aqueles que se opõem a este caminho rumo à modernidade, ou à modernidade em si, são discursivamente excluídos da nação.

Nos textos de García, os limites sociais da nação assim construídos coincidem com fronteiras físicas. Embora todo o território nacional componha a nação, ele não é habitado em sua totalidade por cidadãos que correspondam ao seu entendimento do que é ser um cidadão. Aqui García recorre à geografia imaginativa do Peru produzida historicamente, através da qual ele associa as fronteiras da cidadania a adstrições racistas. Assim a Sierra passa a ser uma área que é habitada por uma população indígena retrógrada. Isso representa um obstáculo ao progresso da nação. A resistência ao extrativismo, originária daquela região, é, por conseguinte, definida como um ataque direto à nação. A Selva, por sua vez, passa a ser mostrada como completamente dominada pela natureza, cujos habitantes são irrelevantes para a nação. Resistências contra a exploração do seu território são, dessa forma, apresentadas como ilegítimas e inválidas. Aqui se expressa que, para García, as reivindicações da população indígena não são compatíveis com o pertencimento à nação peruana.

As regiões historicamente construídas expressam-se, no âmbito dos conflitos socioambientais, na forma de desigualdades de poder, uma vez que, a partir delas, são hierarquizados os cabedais de conhecimento das respectivas populações. Como resultado, é negada aos moradores da Selva e da Serra, a capacidade de uso "razoável" de seu ambiente natural. Isso, no âmbito do discurso governamental, tem a função de legitimar a execução de projetos extrativos, mesmo contra a vontade do povo em questão. 
A diferença aparentemente natural entre as regiões, e assim também a diferença da população, ao contrário das fontes históricas estudadas, nos textos de García, não são mais apresentadas como imutáveis. Embora García se valha de adstrições historicamente construídas e atreladas às regiões, ele redefine o seu papel para a nação. Ou seja, a parte civilizada da população peruana, representada pelo governo García em aliança com investidores privados, tem a missão de estender o controle da costa sobre todo o território e, assim, harmonizar o corpo social da nação com seu corpo físico. Da mesma forma, a orientação para o progresso, de inspiração europeia e tida como base da identidade nacional, precisa ser estendida para a população indígena. O racismo é, dessa forma, reproduzido pelas adstrições feitas à cada região. A conexão disso com a geografia inventada oferece, assim, a possibilidade de desenvolver argumentos racistas dentro de regras discursivas atuais, "politicamente corretas". Embora a diferença tenha sido segregada espacialmente na jovem república, essas áreas de diferença devem ser agora incorporadas à nação conforme as regras da "racionalidade ocidental".

O extrativismo torna-se, portanto, um projeto de integração cultural e territorial sob a bandeira do progresso e do desenvolvimento. Nos conflitos em torno da exploração de recursos naturais, há, para o governo, mais um jogo do que o crescimento econômico. Trata-se também de um projeto político para a conservação do poder hegemônico de definir a identidade nacional. A construção da Sierra e da Selva como espaços que precisam ser "trabalhados" a partir do exterior, em favor do benefício da nação, enfraquece a capacidade dos respectivos moradores no sentido de influenciar o uso de seus habitats. As adstrições racistas a esses habitats têm a função de deslegitimar protestos das populações que neles vivem. Daí que um projeto que supostamente é orientado por princípios de racionalidade e promoção do bem-estar de todos os peruanos se transforma em uma ferramenta de reprodução do racismo e da desigualdade.

\section{Referências}

ALIMONDA, Héctor. La Naturaleza Colonizada - Ecologia politica y mineria en América Latina. Buenos Aires: CLACSO, 2011.

ANDERSON, Benedict. Imagined Communities - Reflections on the Origin and Spread of Nationalism. New York: Verso; New Left Books, 1996.

ARRUNÁTEGUI, Carolina. El racismo en la prensa escrita peruana: Un estudio de la representación del otro amazónico desde el análisis crítico del discurso. Discurso \& Sociedad, v. 4, n. 3. p. 428-470, 2010.

ASHER, Kiran; OJEDA, Diana. Producing nature and making the state: Ordenamiento territorial in the Pacific lowlands of Colombia. Geoforum, 40, p. 292-302, 2009.

BRAIG, Marianne; HUFFSCHMID, Anne. Más allá de Habermas: Lo público como arena y objeto de debate. p. 11-26. In: BRAIG, Marianne; HUGGSCHMID, Anne. Los poderes de lo público: debates, espacios y actores en América Latina. Frankfurt am Main/Madrid: Vervuert, 2009. 
BEBBINGTON, Anthony. Mineria Moviemientos Sociales Y Respuestas Campesinas: una ecologia politica de transformaciones territoriales. Lima: Instituto de Estudios Peruanos, 2007.

CEPAL. Informe Macroeconómico Perú. Lima, 2012.

DE ECHAVE, José C.; HOETMER, Raphael; PALÁCIOS PANÉZ, Mario. Mineria y Territorio en el Perú. Lima: UNMSM, 2009.

DEFENSORÍA DEL PUEBLO. Reportes de Mensuales de Conflictos Sociales. Disponível em: <http://www.defensoria.gob.pe/temas.php?des=3\#r>. Acesso em: 12 jun. 2014.

DIETZ, Kristina. Sozial-ökologische Ungleichheiten. Zum Verhältnis von Gesellschaft, Natur und Demokratie in Lateinamerika. In: H.-J. B.; WEHR, Ingrid. Soziale Ungleichheiten in Lateinamerika. Neue Perspektiven auf Wirtschaft, Politik und Umwelt. Baden-Baden: Nomos, p. 107-136, 2011.

ESCOBAR, Arturo. Territories of Difference. Durham \& London: Duke University Press, 2008.

. Worlds and Knowledges otherwise. Cultural Studies. v. 21, n. 2-3.

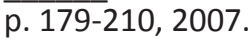

FOUCAULT, Michel. Der Wille zum Wissen. Sexualität und Wahrheit 1. Frankfurt am Main: Suhrkamp, 1983.

GARCÍA PÉREZ, Alan. El perro del hortelano contra el pobre. El Comercio, 2 mar. p. 4, 2008.

. El síndrome del perro del hortelano. El Comercio, p. 4, 28. out. 2007a.

. Estas personas no son ciudadanos de primera clase... Disponível em:

$\overline{\langle h t t p s: / / w w w . y o u t u b e . c o m / w a t c h ? v=y j z x|1| B s w c\rangle . ~ A c e s s o ~ e m: ~} 14$ jun. 2009.

. Receta para acabar con el perro del hortelano. El Comercio, 25, nov. 2007b.

GREENE, Shane. Entre lo Indio, lo negro y lo Incaico: La Jerarquia Espacial de la

Differencia en el Perú Multicultural. Tabula Rasa. v. 13. p. 111-146, 2010.

GRILLO, Maria Teresa; SHARON, Tucker. Peru's Amazonian Imaginary. In: ALEX, Latta; HANNAH, Wittman (Orgs.): Environment and Citizenship in Latin America: Natures, Subjects and Struggles. New York: Berghahn Books, p. 112-126, 2012.

JÄGER, Siegfried. Kritische Diskursanalyse. Eine Einführung. 6. Vollständig überarbeitete Auflage. Münster: Unrast, 2012.

LINDNER, Keith; STERSON, George. For Opacity: Nature, Difference and Indigeneity in Amazonia. Canadian Journal of Cultural Studies, Topia, p. 41-61, 2009.

MÉNDEZ, Cecilia G. De indio a serrano: nociones de raza y geografiá en el Perú. Historica, v. 35, p. 53-102, 2011.

MESCLIER, Evelyne. De la Complementariedad a la Voluntad de "Aplanar los Andes": Representaciones de la Naturaleza y Pensamiento Económicoy Politico en el Perú del Siglo XX. Bulletin d I'institut francais d'etudes andines, ano 30, v. 3, p. 541-562, 2001. 
MICHEL, Boris. Für eine poststrukturalistische Perspektive auf das Machen und die Macht von Karten. Replik auf Ball und Petsimeris. Forum Qualitative Sozialforschung, ano 11, v. 3, 2010.

MOECKLI, Jane; BRAUN, Bruce. Gendered natures: feminism, politics and social nature. In: CASTREE, Noel; BRAUN, Bruce. Social Nature: Theory, Practice, Politics. Oxford: Basil Blackwell, p. 112-132, 2001.

NOGUÉS, Joan. Nacionalismo y territorio. Lleida: Editorial Milenio, 1998.

ORLOVE, Ben S. Putting race in its Place: Order in Colonial and Postcolonial Peruvian Geography. Social Research. v. 60, p. 301-336, 1993.

PAZ SOLDÁN, Mateo. El perro del hortelano contra el pobre. El Comercio, 2 mar. p. 4, 2008.

. Geografia del Peru. Band 1. Paris: Impresores del Instituto de Francia, 1862.

. Mapa general del Peru. Paris: Libreria de Augusto Durand, 1865.

PÉREZ, Alan. El síndrome del perro del hortelano. El Comercio, p. 4, out. 2007a.

. Estas personas no son ciudadanos de primera clase.... Disponível em:

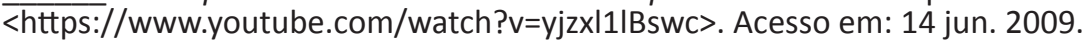

. Receta para acabar con el perro del hortelano. El Comercio, 25 nov. 2007b.

PERREAULT, Tom. Nature and Nation: Hydrocarbons, Governance, and the Territorial logics of Resource Nationalism in Bolivia. In: BEBBINGTON, Anthony; BURY, Jeffrey.

Subterranean Struggles: New Dynamics of Mining, Oil and Gas in Latin America. Austin: University of Texas Press, p. 38-69, 2013.

PERREAULT, Tom; VALDIVIA, Gabriela. Hydrocarbons, popular protest and national imaginaries. Ecuador and Bolivia in comparative context. Geoforum, n. 41. p. 689-699, 2010.

PIZARRO, Ana. Imaginario y Discurso: La Amazonia. Revista de Critica Literaria Latinoamericana, ano 31, v. 61. p. 59-74, 2005.

QUIJADA, Mónica. El paradigm de la homogeneidad. In: QUIJADA, Mónica; BERNAND, Carmen; SCHNEIDER, Arnd. Homogeneidad y nación. Con un estudio de caso:

Argentina, siglos XIX y XX. Madrid: CSIC, p. 15-56, 2000.

RADCLIFFE, Sarah A.; WESTWOOD, Sallie. Re-Making the Nation: place, politics and identity in Latin America. London: Routledge, 1996.

SHARP, Joanne P. Publishing American identity: popular geopolitics, myth and the Reader's Digest. Political Geography, ano 2, v. 6. p. 491-503, 1993.

SUNDBERG, Juanita. Placing Race in Environmental Justice Research in Latin America. Society \& Natural Resources, v. 21. p. 569-582, 2008.

VICH, Victor. El discurso sobre la sierra del Perú: la fantasia del atraso. Critica y Emancipación, v. 3, p. 155-168, 2010. 